\title{
Empowering Faculty to Support Academic Persistence through a Blended, Scholarship-Based Faculty Professional Development Program: The Persistence Scholars Program
}

\author{
Michelle D. Miller \\ Northern Arizona University \\ K. Laurie Dickson \\ Northern Arizona University \\ Rachel L. Koch \\ Northern Arizona University
}

\begin{abstract}
While it is well-known that faculty-student interaction is key to student success, few institutions have directly leveraged faculty in supporting academic persistence. Many myths about persistence proliferate, and faculty can unwittingly hinder persistence by implementing the wrong kinds of practices. Faculty are most empowered to support student persistence when they understand and care about this issue. They are also better equipped to belp when they have a good, current command of the body of knowledge relating to persistence. To address this, we created a blended faculty development program to engage faculty in the scholarship of academic persistence, addressing myths and misconceptions about persistence, and expanding understanding of what it is like to be a firstyear student at our university. The Persistence Scholars Program engaged a total of 32 faculty over two semesters, beginning with pre-readings and an in-person daylong workshop followed by an eight or tenweek course. The curriculum was built around a central text, Completing College by Vincent Tinto, and selected empirical and germane articles. Participants engaged in online discussions and two experiential projects, including one that asked them to complete an activity that would enhance their understanding of first-year students' experiences. Assessments of this program focused on participant ratings of target competencies (e.g., the ability to identify and dispel myths about why students persist), perception of usefulness of different specific assignments and materials, and suggestions for how the program can be refined for future cohorts.

Keywords: academic persistence, mindset, faculty professional development, student retention, first-year students
\end{abstract}

Given the social, health, and economic benefits of an undergraduate education, there is a national call to increase college completion rates and reduce inequities. According to the Commission on the Future of Undergraduate Education (2017, p. 4), “about 60 percent of students who pursue a bachelor's degree complete one. And about 30 percent who pursue a certificate or associate's degree earn the credentials they seek. And completion rates, when analyzed by gender, race, ethnicity, and socioeconomic status, reveal substantial inequalities." Northern Arizona University's participation in the AASCU Re-Imagining the First Year of College (RFY) initiative grows out of our commitment to improve undergraduate education-particularly for underserved populations - and the premise that changing the college experience for students during their first year is the key to achieving that goal.

We know that the institutions that are most successful in retaining students are the ones in which there is concerted, coordinated effort across the institution to help students persist. To make the most of student persistence initiatives, everyone in the institution needs to be working together: 
leadership, advising, residence life and yes, faculty. Faculty hold the keys to the student academic experience, which in turn, plays a critical role in retention and degree completion. Vincent Tinto puts it this way:

If institutions are to significantly increase the retention and graduation of their students, especially those from low-income backgrounds, their actions must be centered on the classroom. They must focus on improving success in the classroom, particularly during the first year and lead to changes in the way classes are structured and taught and, in turn experienced by students, especially those who have not fared well in the past. (Tinto, 2012, p. 15)

Given the fundamentally important role that faculty play in student success, we focused our RFY attention on building the capacity of faculty to more fully engage in our efforts. Complementing our institutional efforts such as monitoring predictive analytics, sending automated alerts to students, redesigning curriculum to make pathways clear and coherent, expanding advising and offering supplemental instruction, we aim to empower faculty to become informed, effective advocates for practices that support student persistence. Faculty have the power to positively affect persistence through the ways in which they teach and interact with students, as well as by advocating for the right kind of institutional policies.

Academic persistence is backed by a rich and informative literature about how academic persistence works among students from diverse backgrounds and in diverse settings. However, the people best placed to influence students' persistence in college courses-faculty-tend to have less familiarity with this work. In other words - just as faculty sometimes enter the profession without direct instruction on how to teach, they enter without understanding how to help students persist. This lack of familiarity can include the body of scholarly work and also knowledge about one's own home institution.

In such an environment, myths about persistence proliferate, and faculty who are otherwise quite committed to student success can unwittingly hinder persistence by implementing the wrong kinds of practices or giving the wrong kinds of messages to students. Furthermore, even those who do implement the right practices may stop when they encounter criticism from peers or other types of pushback. Even if the majority of faculty don't believe outdated ideas, such as that college should be a weeding-out process or that the only way to promote retention is to admit better students, the more vocal critics can dominate the dialogue.

Faculty are most empowered to support student persistence when they understand and care about this issue. They are also better able to overcome pushback when they have a good command of the body of knowledge relating to persistence, students' experiences at their institution, and their institution's efforts to support student success. This mastery is best created by offering the opportunity for critical inquiry, application to one's own discipline, and active interrogation of data, as opposed to passive exposure to facts, figures, and prescriptive advice.

\section{The Persistence Scholars Program}

We created the Persistence Scholars Program (PSP) to empower faculty to become informed, effective users of and advocates for practices that support student persistence. We envisioned this program as a faculty professional development experience, but unlike most such experiences, which tend to be organized as one-to-three day conference or workshop events, PSP extends over multiple weeks within a semester. 
Besides the extended time of participation, there are other important characteristics that set PSP apart from typical faculty professional development programs. PSP is structured as a blended learning course, with face-to-face components bracketing an asynchronous online course. Core readings, consisting of a central text-Completing College by Vincent Tinto-and selected empirical articles, ${ }^{1}$ anchor these parts of the program, serving as the basis for the online discussions. These readings were chosen specifically for their focus on institutional and pedagogical factors that can help or hinder academic persistence. In contrast to typical faculty professional development programs, they did not focus on development of basic pedagogical skills, which we believe are adequately served by other resources and programs.

Another key component of PSP are two assignments, the Field Project and the Application Project. Conceived not as conventional academic research papers but rather as documentation of selfdesigned experiential learning projects, these assignments offered the opportunity for participants to put into practice the concepts encountered in the scholarly readings side of the course. With the overarching goal of building deep understanding of issues (social, emotional, logistical, academic) relating to persistence, the intent of these assignments was to engage faculty in experiencing some aspect of campus life from the student perspective and to encourage them to make substantive changes to their own practices based on what they learned in the program.

We designed the course to engage university faculty across disciplines, with an approach that emphasized a combination of scholarly work and first-person application and perspective-taking. Our desired outcomes for participants were that they be able to:

- Explain the major factors that contribute to student attrition at the course level and institution level

- Identify trends, disparities and other important patterns in student persistence data at national, university, and department/college levels. In other words, participants will be able to give an evidence-based answer to the question: Who persists, who drops out, and why?

- Identify and dispel some of the major misconceptions about attrition and persistence

- Discuss and apply concepts from the research literature on persistence

- Use the capabilities listed above to effectively advocate for practices that promote student persistence

In this article, we will describe the Persistence Scholars Program, including its initial iteration in Fall 2017 and the second, revised iteration in Spring 2018. Following the presentation of quantitative and qualitative assessment data for both iterations, we offer observations that include the perceived strengths of the program, unexpected outcomes, and recommendations for institutions wishing to set up similar professional development programs focused on academic persistence.

The primary way we recruited participants was by connecting the PSP to another large, established program at our institution: the First Year Learning Initiative, or FYLI. The FYLI program certifies gateway and lower-division courses that, through a process of reflection and redesign, have implemented design and pedagogical practices that support student success (for additional details on FYLI, see Miller \& Scarnati, 2014). This program provided us with a ready-made audience of over 100 faculty and staff affiliated with these courses, whom we could contact with recruiting emails in the months leading up to the launch of the PSP. We also offered FYLI courses the opportunity to extend

\footnotetext{
${ }^{1}$ Our reading lists, program syllabus, instructions for interactive learning activities, and complete assessment instruments are all available on request. For copies, please contact the corresponding author, Michelle Miller, via email: michelle.miller@nau.edu.
}

Journal of the Scholarship of Teaching and Learning, Vol. 19, No. 1, February 2019. josotl.indiana.edu 
the certification of their courses — which otherwise involved a fairly demanding set of recertification activities - if two or more core faculty members completed the PSP. In addition, we provided an honorarium of $\$ 150$ in professional development funds and a copy of Completing College. Michelle Miller $(\mathrm{MM})$, the Director of the FYLI program, facilitated the first PSP cohort.

\section{Cohort 1: Fall 2017}

\section{In-Person Kickoff Meeting}

This was the only synchronous or face-to-face component required of participants. Lasting approximately five hours, the kickoff meeting was intended to build enthusiasm, frame the program topics and objectives in a powerful way, offer an opportunity to address questions, and allow participants to get acquainted with one another and with the facilitator prior to the online component. It also included a hands-on data exploration exercise, described below.

Participants were asked to complete several readings and view a 25-minute video prior to the meeting. Table 1 gives an overview of the program schedule as well as a week by week break down.

\section{Table 1. Overview of program schedule and components.}

Week number

Week 0

Week 1

Week 2

Week 3

Week 4

Week 5

Week 6

Week 7
Main activities

In-person kickoff meeting

Read Tinto Chapter 2, "Expectations"

Read Tinto Chapter 3, "Support"

\section{Read Tinto Chapter 5,} "Involvement"

Read article on lay theories and mindset

Read article on transparency in course design/pedagogy

Work on field project

Read article on the impact of small-stakes assessment on achievement gaps

Work on application project
Due from participants

Complete pre-reading and Tinto Chapter 1 and view assigned video on student persistence

Post about Chapter 2

Post about Chapter 3

Post about Chapter 5

Post about the lay theories article in online discussions, Submit plan for the field project

Post about the transparency article in online discussions

Post about the achievement gap article in online discussions

Journal of the Scholarship of Teaching and Learning, Vol. 19, No. 1, February 2019.

josotl.indiana.edu 
persistence at NAU

Week $8 \quad$ Complete field projects

Week 9 Complete application projects

Week 10 discussions, Share resources for NAU persistence data in the course wiki

Post about field project in online discussions Submit write-up of field project

Post about application project in online discussions, Submit write-up of application project

Post reflections in online discussions Exit assessments

Introductions, framing presentation, and discussion. After leading an icebreaker introduction exercise and offering an overview of the day, the facilitator invited participants to write down on a half sheet of paper one or more reasons they have heard, or that they themselves believed, about why students drop out of college. Example reasons included "lack of social support," "lack of interest in content," "working long hours," "immaturity," and "do not know what the discipline is."

Participants posted these sheets on an 8'x4" "sticky wall" that allowed them to easily review all the posts at once. The subsequent discussion focused on whether these reasons were supported, or not supported, by evidence, and any patterns participants noticed.

The framing presentation followed this discussion. It consisted of slides interspersed with discussion, anchored around "Five Key Claims" about persistence, which served as a philosophical anchor and framework for the rest of the program. Table 2 lists the Five Key Claims.

\section{Table 2. Five key claims}

1. Persistence matters (for individuals, for communities, for the nation and world).

2. Significant disparities exist with respect to persistence; these both reflect and perpetuate ethnic, class, and economic inequalities.

3. We know a lot about how persistence works:
a. The kind of teaching that students experience matters
b. Institutional environment and policies matter
c. The early college experience is especially important
d. Student expectations of us, our expectations for students, belongingness/connections, and support are all major influences

4. There are effective strategies for addressing disparities and increasing persistence in general, although these are not always easy or cheap to carry out in a sustained fashion.

5. Faculty have the power to positively affect persistence through the ways in which they teach and interact with students, as well as by advocating for the right kind of institutional policies. 
Guided data exploration activity. This one-hour activity involved participants in exploring empirical evidence relating to claims about academic persistence. For example, if they believed that work hours predicted persistence, they could search online for data relating paid work to metrics such as GPA or graduation rates. Participants worked in pairs and reported out to the larger group at the end of the hour. We provided loaner laptops, and representatives from the university library circulated during the activity to answer questions and provide additional guidance.

Guest presentation. Our Associate Vice President of the Office of Enrollment Management and Student Affairs provided an overview of the history of and major milestones in the academic study of persistence.

\section{Online Course}

The online component of the PSP was divided into three modules: Setting Conditions for Persistence, Interventions and Strategies, and Persistence at NAU. There was also an abbreviated closing module called Wrapping Up. Each of the three main modules was divided into three one-week segments.

Most of the one-week segments focused on one or two assigned readings, either chapters from Completing College or journal articles. We provided framing questions prior to the readings and facilitated an online discussion about the readings. The discussion prompts were typically open-ended, asking participants to offer their reactions, insights or other comments pertaining to the readings.

As an example, below is the assigned reading and framing questions for week 2 of the course, within the Setting Conditions for Persistence module:

Please read - Tinto book, Chapter 3: Support

This chapter focuses on the role of support - academic, social, financial - on student success.

As you read it, please pay particular attention to Tinto's claim that academic support is the most important form of support. How does academic support work, according to Tinto, and what are the most effective ways of providing it to diverse student populations?

Also consider: What are the most important things you think faculty should know about other forms of support (financial and social)? Are there particularly successful or interesting interventions (for any type of support) that you notice from the example institutions Tinto presents?

The online course also focused on the two projects. Participants posted about their projects within discussion boards, and the module folders also contained reminders and information about the projects. The first of these was the field project, as follows:

The purpose of this assignment is to give you a first-hand experience of some aspect of what it is like to be a student at NAU, through the student perspective. You'll choose some activity, or realistic simulation, that captures some aspect of the student experience. For example, you might go on a campus tour, attend an orientation for a program, sit in on a gateway class, or complete a simulated advising appointment. Please feel free to be creative and choose something that will give you a new view of our institution from the student side.

This assignment was split into two parts, first, an informal 1 to 3 page description of the planned activity and reasons why the participant chose it. The second part consisted again of an informal 1 to 3 page summary and reflection about the activity.

Journal of the Scholarship of Teaching and Learning, Vol. 19, No. 1, February 2019. josotl.indiana.edu 
For the second of the two projects, the application project, participants submitted another short written summary of how they planned to apply what they learned in the PSP to either their own practice, or how they planned to disseminate it to colleagues.

Assessment

We designed two online exit surveys to serve as assessments, focusing on participant perceptions and self-reported impacts, particularly those that mapped onto the desired outcomes. These included open-ended comment-style questions as well as closed-ended Likert-style questions.

These were split into two separate surveys, one non-anonymous and one fully anonymous. Having one of each type allowed us to require the survey as a condition of completing the course, as we could see who finished the non-anonymous one (and offer personal reminders to those who had not turned in the survey), while allowing participants to submit completely candid responses on the anonymous one.

\section{Outcomes and Observations from Cohort 1}

Completion rates. Twenty-two participants signed up for the program and attended the kickoff workshop. Of these, $19(86 \%)$ completed all or most of the online coursework, and were awarded certificates of completion, while the remaining were missing major parts of the online coursework, and/or stated partway through that they would not be able to complete the program.

Projects. Application projects tended to focus on participants' own teaching practices, although several did choose dissemination to colleagues as an option for applying concepts from the program. Example planned applications included:

I will change my teaching practice by more meaningfully implementing lay theory.

I am curious to what impact it may have on exam grades if the students take a quiz, every Thursday throughout the semester, except when they have exams or when we have guest speakers on those days.

I plan to incorporate the small stakes assignment in a class I have not taught before.

I would like to create a resource for the Academic Transition Programs, and then post it on our ATP Resource Folder housed on BBLearn.

Several participants reported that they had piloted or implemented these proposed changes during the PSP semester, including:

The NAU 120 course that I am teaching this semester includes mandatory weekly meetings with a biology mentor to review BIO 181 content as well as provide a mentor relationship for each student.

My goal was to encourage my students to use the Writing Commons to get support on their final paper. As an incentive, I offered them 25 extra credit points.... Out of my approximately one hundred NAU 130 students, I would say at least one-third told me they planned to use the writing center.

Field projects were, in our opinion, the standout experience of the PSP. The most popular types of field experience were those in which the participants went through some resource or program, such as advising or tutoring, in the role of a student. Participants frequently reported that this Journal of the Scholarship of Teaching and Learning, Vol. 19, No. 1, February 2019. josotl.indiana.edu 
highlighted the importance or value of these resources, or gave other insights about how they might help support student success:

The field project that I chose was to observe biology mentors during their tutoring sessions with my NAU 120 students... I have observed several mentoring sessions over the past couple of weeks and so far I have been impressed with the level of knowledge that each of the mentors have, not only of BIO 181 content, but also about $N A U$ and the college experience.

For my Field Project Experience, I scheduled an appointment with the Writing Commons.... For a more "real" experience, I searched for a paper I wrote a few years ago while in graduate school at $N A U$.... I learned quite a bit from this experience. It was helpful for me to understand the process because I can now tell students what to expect. I am offering Extra Credit to my students to visit the Writing Commons for the final paper. I actually took my edited paper into my classes and showed them that even I was able to get helpful feedback on a graduate level paper. I think that also helped normalize the idea of going for many of them.

I chose NAU's Academic Success Centers as my project site in order to learn what sort of academic support students could get on campus, and how that support is related to the student retention rate. Thus, I conducted tutoring observations and individual interviews with the staff and tutors.... This triggered a shift in my understanding of the problem as I had earlier assumed that students struggled more with lesson content rather than with more general issues related to transitions and/or adjustments. These findings came as a significant 'ah-ha' moment for me and delivered a larger understanding of the problem.

Here, I report on my experience for attending an initial pre-med advising workshop at $N A U$.... The workshop was run by two advisors who delivered a presentation on the different types of medical programs and how to prepare for medical schools applications while at $N A U$. They described the entrance requirements and how to work towards satisfying them. Also, they outlined how to compile an application and mentioned some tricks to stand out.... My favorite part of the presentation was a schedule that specified what to do and when.

In a twist on the student-perspective approach, several participants chose to attend one or more classes in an unfamiliar discipline (e.g., math and physics, in the case of an English professor, or a first-year seminar, in the case of a Global Languages professor):

One of the things that I noticed is that the Peer TA is referred to as the Peer Facilitator. And his role during that class period was exactly that. He was participating in the discussion and adding insightful information about the topic and [at] the end of the class he was suggesting new topics to discuss with the instructor for upcoming classes.

The instructors and the approach to instruction made it okay for me to be a little lost or to be wrong. I'm so grateful to work at a university where teaching is a priority and folks are good at it. Really good! The students at $\mathrm{N} A U$ are really lucky.

Exit assessment surveys. Seventeen participants ( $94 \%$ of program completers) responded to the nonanonymous survey and 19 responded to the anonymous survey $(100 \%$ of program completers, or $86 \%$ of all those who started the program; we are unable to determine whether any non-completers completed the survey as it went out to all who enrolled).

The first, non-anonymous survey began by asking about any planned changes to one's own teaching practice based on the program. Example comments included:

Journal of the Scholarship of Teaching and Learning, Vol. 19, No. 1, February 2019. josotl.indiana.edu 
Miller, Dickson, and Koch

Emphasizing formative assessments more in my classes; speaking directly to the factors that increase persistence

Announcing a course plan that lays out how many assignments are required and when they will be announced/due

More culture, added support for learning methods outside of the classroom, more quizzes, more emphasis on participation at university events

Communication with colleagues was then queried. Example comments on this topic included:

I think I will be more confident and proactive in discussing misconceptions as well strategies that colleagues could use to support students.

While my colleagues are quite attuned to student needs, I plan to reinforce the statistics and interventions we have learned about in class.

I feel like I have already made changes this semester with respect to discussions with colleagues and topics we covered in this program. Some of my colleagues have always sort of just blamed the students if they are not doing well, but I have already started discussing different factors that make it difficult for many students, like having to work full time, and what are some things we can maybe do to help them.

Participants were then asked to list the three most important takeaways from the program. Of takeaways listed as first in importance, 35\% involved values or conceptual understanding pertaining to persistence, e.g., "persistence and belonging go together" or "student persistence is complicated and multi-layered." The next most prevalent responses, $24 \%$, involved concepts from the readings, e.g., "learning about the concept of transparency in teaching." Responses involving student support techniques and resources were next at 18\%, e.g., "engagement with students." Remaining responses involved appreciation of student perspectives, e.g., "appreciation for the struggles students go through," and specific teaching/course design techniques, e.g., "small-stakes assignments" (12\% each).

Subsequent items asked participants to self-rate their knowledge about student persistence before and after the program, using a Likert-style scale where $1=$ Not knowledgeable at all and $5=V$ ery knowledgeable. Mean ratings before the program were $2.59(S D=1.23)$, compared to $4.18(S D=.73)$ after the program, a difference that was statistically significant at an alpha level of .05 (paired $t=$ 6.154, $d f=16, p<.001)$.

Participants also rated their competency with skills pertaining to persistence, where $1=I$ could not do this at all and $5=I$ could do this very well. Mean ratings are presented in Figure 1. Ratings for these items were all well above midpoint, with the lowest-rated skill being "Identify trends, disparities and other important patterns in student persistence data" $(M=3.82)$ and the highest-rated skill being "Explain the major factors that contribute to student attrition" $(M=4.24)$.

Journal of the Scholarship of Teaching and Learning, Vol. 19, No. 1, February 2019. josotl.indiana.edu 


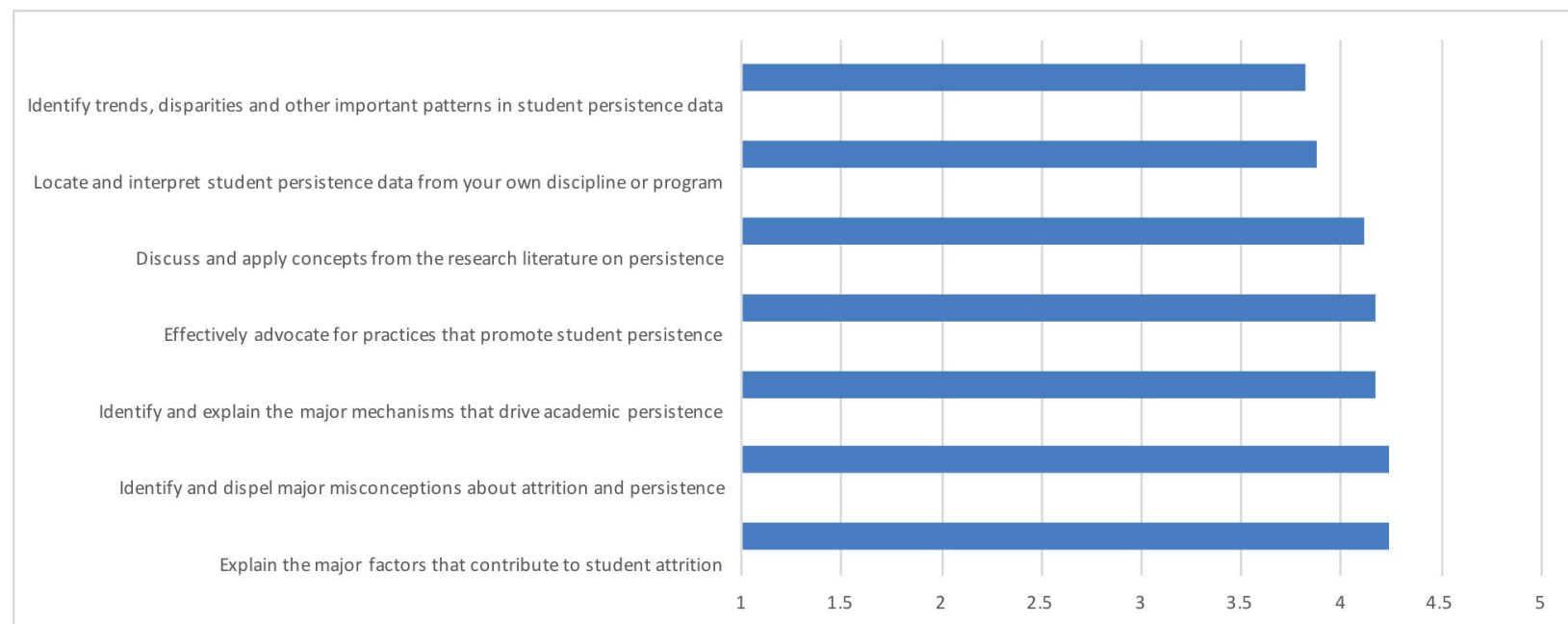

Figure 1. Mean self-rated competency on skills pertaining to persistence, ranked from lowestrated to highest-rated.

Comments pertaining to who would benefit from the program in the future included several who mentioned new faculty, and several who cited faculty who teach a large proportion of first-year students, or who taught FYLI courses. Interestingly, several other respondents cited the opposite, including faculty who do not teach first-year students regularly and senior/tenured faculty, as well as upper administration. The final item inviting comments about the program elicited remarks from only four individuals; all four comments were variations on having learned a lot from the program.

Turning now to the anonymous survey, the first item asked participants to rate their overall opinion of the value of PSP as a professional development experience, on a scale where $1=$ Not very valuable and $5=V$ ery valuable. The mean rating was 3.95 , with Very valuable as the most frequently selected option (11 out of the 19 total responses, or 58\%). Participants could offer comments on this question as well; of the six comments offered, four were uniformly positive, e.g., "As a new instructor at NAU, this course did help me think about various issues from different angles. Sharing ideas with other peers was definitely helpful." The two remaining comments were mixed, e.g., "Content is generally useful, but way it was presented made it less engaging."

The next several items asked about the effectiveness of specific components of the program on a three-point scale, $1=$ Not effective, $2=$ Somewhat effective, and $3=$ Highly effective. Frequencies for these are shown in Figure 2. Ratings for these different components were generally good, with the lowest-rated being the online discussion boards and the highest-rated being the initial in-person workshop). 


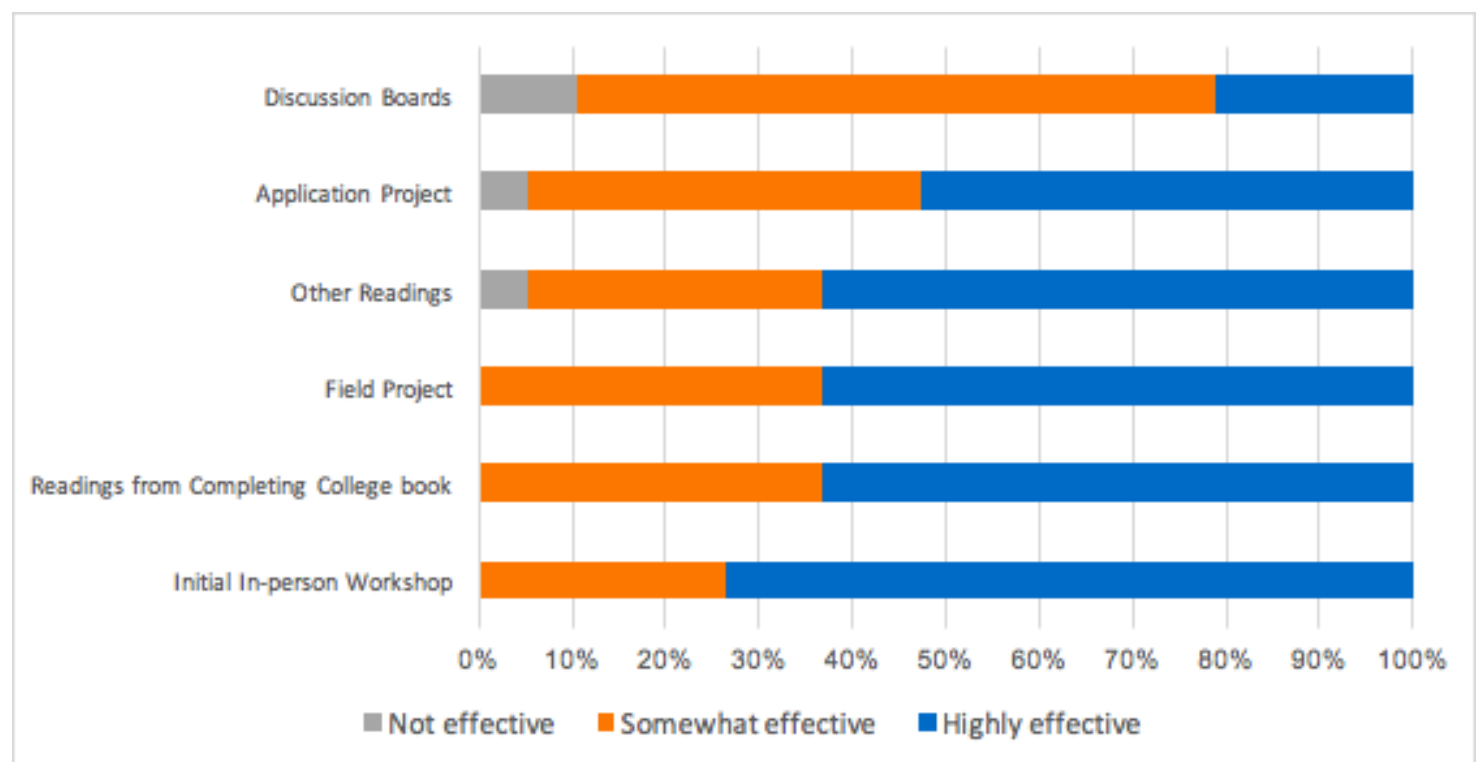

Figure 2. Frequency counts for the effectiveness of different components of PSP, ranked from lowest-rated to highest-rated.

The overall high ratings for the kickoff workshop are important, especially given that this part is particularly labor- and resource-intensive. However, a caveat is that 4 of 6 open-ended comments were either moderately negative ("could have drilled in to major information in a more direct fashion"), or mixed ("it was great to be with other faculty, but I would have liked to engage more with those folks and the material in person"). Only two were entirely positive, and one of those simply stated "I do better with face to face."

This last comment in particular echoes some other suggestions that faculty are not generally enthused about the blended format, with comments on later items such as "I have never been a fan" of online discussions or that they were confused about how to use the wiki function within BlackBoard Learn. Several respondents stated that they would have preferred additional workshops or other types of face to face meetings.

Ratings on other items followed this pattern of generally positive, but mixed. Regarding the length of the program, responses were: $50 \%$ about right; $33 \%$ somewhat long, $11 \%$ definitely too long, $6 \%$ somewhat short, and $0 \%$ definitely too short. For the pace of the program, responses were: $55 \%$ about right; 6\% somewhat slow, 6\% definitely too slow, 33\% somewhat fast, and $0 \%$ definitely too fast.

Particularly important for our second iteration of the program were the ratings on the two survey items asking what resources the participants believed would have helped them meet the expectations of the program, and suggested changes that would make it more effective. Figures 3 and 4 give the count of responses for each option. (Because these questions were formatted as check all that apply, we have provided response counts instead of percentages). For helpful resources, an online calendar and email reminders were the most frequently listed, followed by more extensive discussion and explanation of expectations. For suggested changes, decreased emphasis on discussion board participation was the most frequently cited, although an equal number of responses cited nothing; the program is maximally effective as it is (i.e., no changes are needed).

Journal of the Scholarship of Teaching and Learning, Vol. 19, No. 1, February 2019. josotl.indiana.edu 


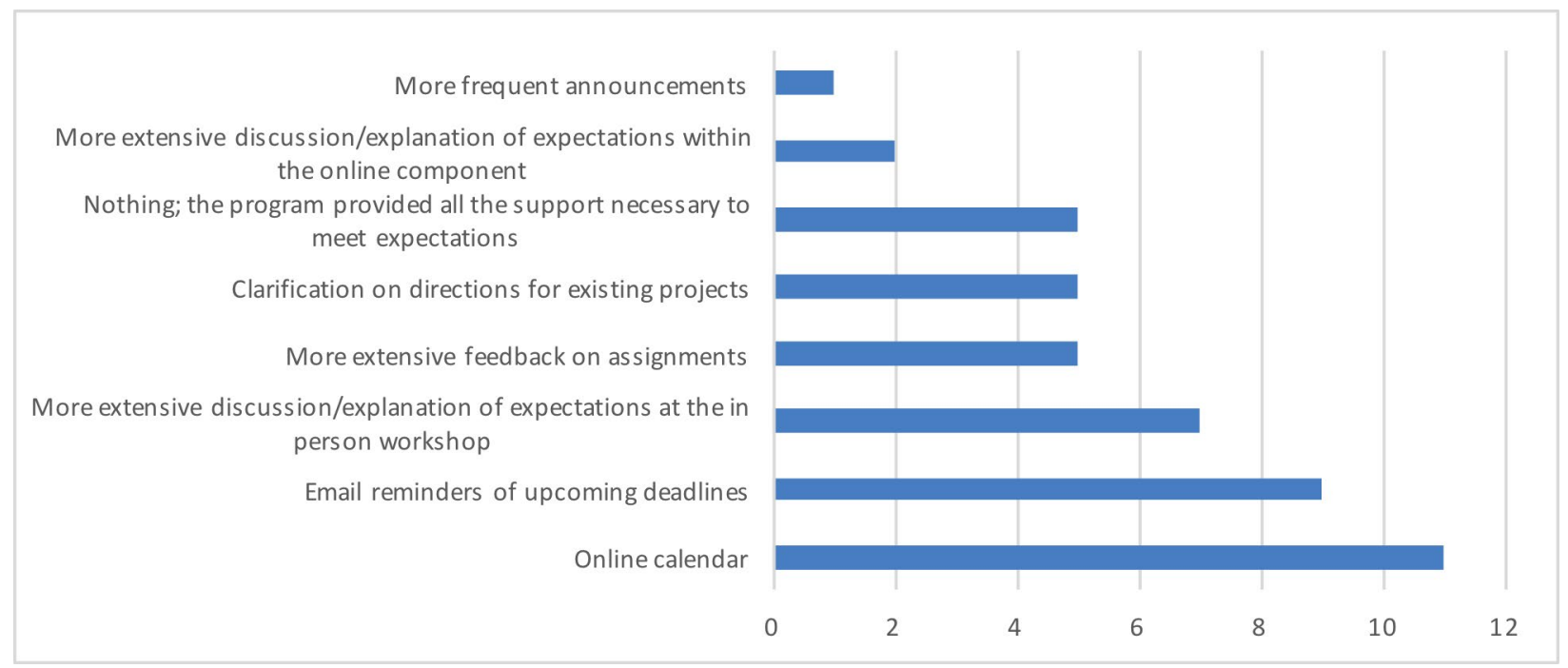

Figure 3. Response counts for which resources would help participants meet the expectations of PSP, ranked from fewest to most responses.

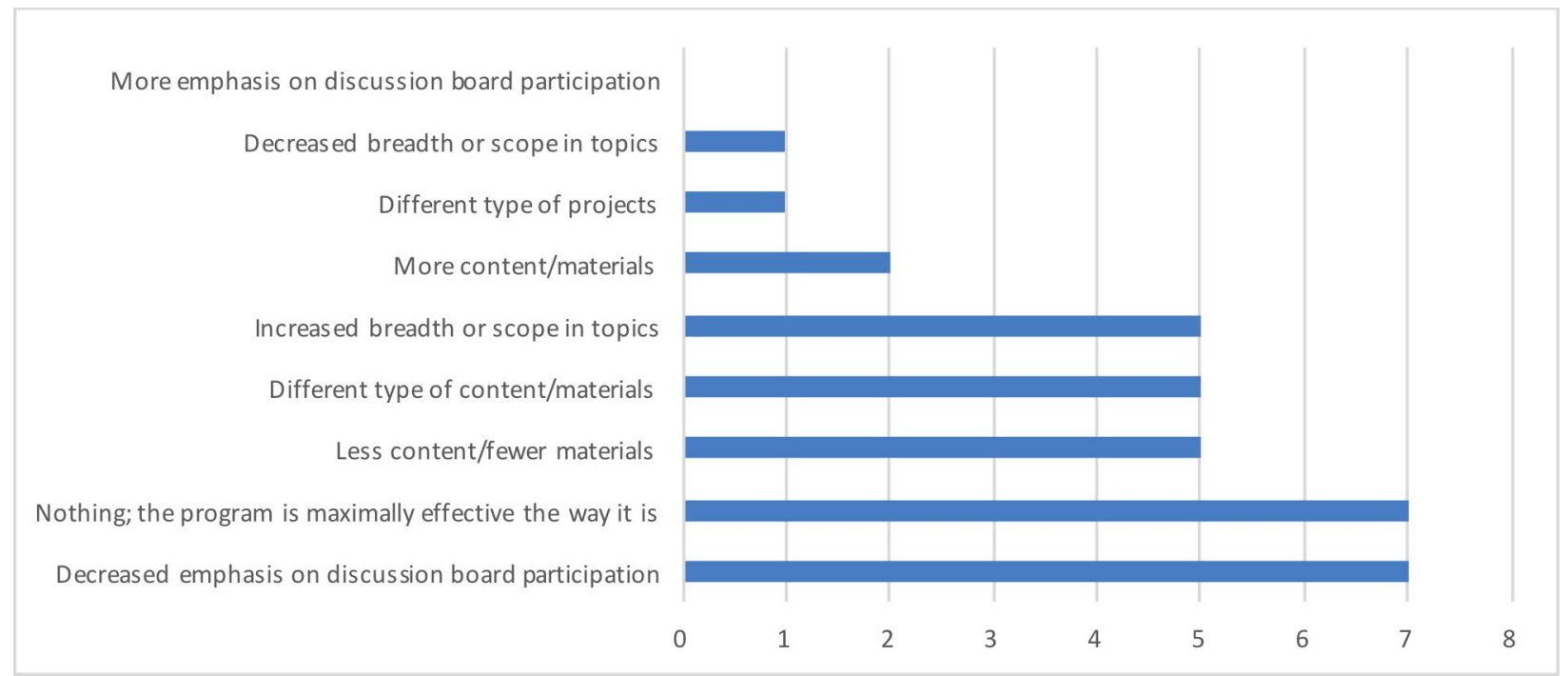

Figure 4. Response counts for what changes would make PSP more effective, ranked from fewest to most responses.

On the remaining survey items, participants rated whether they would recommend the program to a colleague, and made other summary comments about the quality and effectiveness of the program. Several commented that the program workload seemed excessive, or that the workload was appropriate but difficult to manage given other demands on their time during the semester. However, there were several overall positive comments as well, including "Strong point is that education becomes a collaborative and mutual endeavor among all aspects of the institution and student," and "Overall, very good program." In response to whether participants would recommend PSP to colleagues, 65\% said Yes, definitely, 30\% said Yes, maybe, and 4\% (one response in total) said No, definitely not. 


\section{Cohort 2: Spring 2018}

Rachel Koch (RK), serving as the Interim FYLI Director, facilitated the second PSP cohort. RK brought a participant-centric perspective to the facilitator role, having been a participant in the first PSP cohort. Based on participant feedback and assessment data, slight modifications were made to the schedule, assignments, and the frequency of in-person engagement.

\section{In-Person Kickoff Meeting}

Similar to the first cohort, the in-person kickoff meeting was intended to build enthusiasm, frame the program topics, offer an opportunity to address questions, and allow participants to get acquainted with one another and with the facilitator prior to the online component. Participants were asked to complete the same assignments prior to the meeting. At the meeting itself, the progression of activities and topics was as follows.

Part 1: Introductions and framing of persistence. After a brief introduction, the facilitator led a 7-minute writing activity. Participants were asked to answer the following questions:

- Why are you here?

- What do you hope to get out of this program?

- What are some of your goals for Persistence Scholars?

Participants shared responses with a neighbor, and following the group discussion, each participant introduced him/herself to the group by answering Attendance Questions when their name was called (name, department, number of years teaching, a goal you hope to achieve from this program). Activities like the Attendance Question activity were directly discussed and offered as models for options attendees might explore in their own courses.

Following the icebreaker, the facilitator shared her goals with participants: to share ideas, to build community, to engage with one another and students in a new way, and to close some loops/locate new resources.

As a way to extend the initial activity - and help familiarize participants with the online learning management system (LMS) — they then posted a response to one of the following questions into the Persistence Scholars BBlearn shell:

- How might this Attendance Question activity be modified for one of your own classes?

- Do you do something similar to engage with students (and take attendance/learn names in a class you teach?

- Do you have a good idea for an attendance question you could ask your students?

The next hour was devoted to an overview of the kickoff session and a discussion of the presession readings in groups. Opportunities for attendees to collaborate were carefully cultivated. Questions about what stood out and how these items relate to their work at the university allowed for an in-depth and meaningful conversation.

A framing of persistence followed this discussion. First, small groups discussed why they believe students fail to persist (including what they hear from other people). Ideas were written on the board and shared in the main group. The "Five Key Claims" about persistence, detailed in Table 2 were also shared to serve as a framework. 


\section{Part 2: Guest presentation, coursework, and projects}

In addition to the academic study of persistence presentation described above, a business analyst provided an overview of retention and persistence tracking efforts at NAU. The presentation included how data are captured, organized, used, and reported, and also described the role of predictive analytics in identifying and supporting student persistence. Participants were encouraged to think about how they might work with data for their Application Project later in the semester.

After lunch, the facilitator spent time reviewing the syllabus, including expectations for the online component, the two experiential assignments, and the upcoming in-person session. As a way of framing the course, participants were asked to approach the course as a conversation: with themselves, one another, the instructor, and with students.

\section{Online Component}

The online component of the PSP was divided up by time period instead of modules. The preorientation materials and each of the eight week's readings and discussion questions were accessible by date. The online discussions and experiential assignments were similar to the first cohort, each oneweek segment highlighted one or two assigned readings, either chapters from Completing College or journal articles. The only major difference was that participants were asked to present their Field Projects to the class in the style of a 3-Minute Research Project.

\section{In-Person Session \# 2}

The second in-person session took place halfway through the eight-week program. It was intended to be a check-in with participants and an opportunity to review the student data approaches that were introduced in the Kickoff session. The session lasted two and a half hours. Participants began by detailing progress on their Application Projects which afforded an opportunity to provide feedback and/or suggestions to the participants as they moved forward.

The second part of the session focused on dissemination. Participants presented their Field Projects to the group in the style of the 3-Minute Research Project. All presentations were recorded and were uploaded on the LMS for participants to download for future use.

\section{Outcomes and Observations from Cohort 2}

Completion rates. Thirteen participants started the course, though only 8 completed the program (60\%).

Exit assessment surveys. The same two online exit surveys served as assessments. Five participants responded to the non-anonymous survey and 6 responded to the anonymous survey. While this response rate represents a reasonable proportion of the overall cohort, it is a small number of surveys overall. We therefore want to strongly qualify all of the quantitative findings for the second cohort, noting the limitations of drawing conclusions based on so few data points.

The non-anonymous survey comments about planned changes to teaching practice included:

Although I provide lists with links to NAU resources, I will be more proactive with students about discussing them. In addition, I will address more specifically the transition to college.

Journal of the Scholarship of Teaching and Learning, Vol. 19, No. 1, February 2019. josotl.indiana.edu 
Miller, Dickson, and Koch

Accentuate the seminar methodology of discussion-based interaction based on assigned materials whereupon students in a collaborative atmosphere grapple with thoughts and concepts derived from readings or discussions. By grappling with thoughts and concepts, the goal for students is threefold, (1) learn to develop and ask questions about the thoughts or concepts, (2) learn to form arguments, supported by facts, and effectively communicate their evaluation regarding the thoughts or concepts, and (3) learn to evaluate presented arguments for consistency and coherence.

More referrals, more academic skills exercises, incorporating evidence about note-taking and with regard to memory cues

For communication with colleagues, example comments included:

I am already as strong an advocate as I can be for my students, and for course and program quality.

During the next fall faculty retreat, $[\mathrm{E}]$ and I will lead a discussion about persistence and specifically address ways faculty can be proactive in their courses.

I'm not sure... It would be situational.

Planning a presentation for the faculty retreat to share all of these new concepts, but also feeling energized about teaching in general and hoping to share that with others

First, I would address the value of the program and the [opportunity] to reframe my approach and methodologies to develop curriculum, create classroom dynamics among students and instructor, and be more attentive to students as persons.

Of the takeaways listed as first in importance, three specifically referenced learning about lay theory, e.g., "I appreciated learning about lay theory. It seems like a no-brainer, but the authors of the article together with my experience on the campus tour really made me think of the importance of addressing the transition to college." Of the two remaining comments, one mentioned expectations, and the other mentioned the importance of the instructor-student relationship.

Mean ratings (on a five-point scale) for self-rated knowledge about student persistence before the program were $2.4(\mathrm{SD}=1.67)$, compared to $4.4(\mathrm{SD}=.55)$ after the program. (We did not test for statistically significant differences between these given the small number of data points.)

Mean ratings (on a five-point scale) for competency with skills relating to persistence are presented in Figure 5. Ratings for these items were all well above midpoint, as they were in Cohort 1, with similar patterns; the two lowest-rated skills and the highest-rated skill and the highest ("Explain the major factors that contribute to student attrition") were identical.

Journal of the Scholarship of Teaching and Learning, Vol. 19, No. 1, February 2019. josotl.indiana.edu 


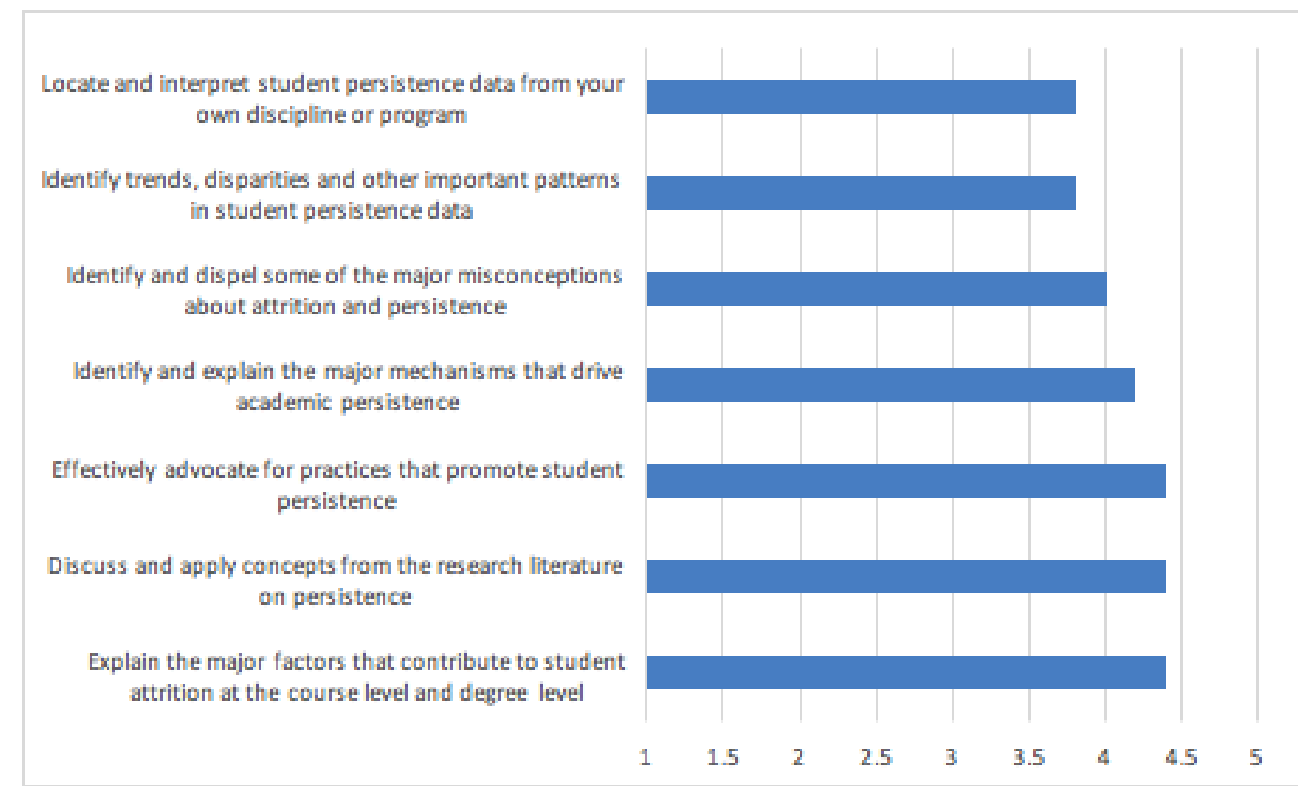

Figure 5. Mean self-rated competency on skills pertaining to persistence, ranked from lowestrated to highest-rated, Cohort 2.

Comments pertaining to who would benefit from the program in the future included new faculty, personnel involved in veteran and military services, and several who cited chairs and others responsible for undergraduate curriculum.

The final item inviting comments about the program elicited additional comments about the impact of the program:

The important thing is to keep bringing more Faculty into it so it puts the issues up front for them.

I appreciate the care that went into crafting the program and the availability of the instructors to address questions and comments.

There was an impact on my personal mindset and awareness of the issues, the data, the processes, which in turn will impact my teaching and interaction practices.

Turning now to the anonymous survey, the mean rating for the overall opinion of the value of PSP as a professional development experience, on a five-point scale, was 4.83 , with Very valuable as the most frequently selected option (5 out of the 6 total responses). This is nearly a full point above the rating on the same item from Cohort 1 (3.94); again, due to the small sample size we did not conduct statistical testing on this difference, but it speaks well of the improvements and relative impressions of the second iteration of the program.

Of the comments offered on the overall opinion item, all three were uniformly positive, e.g., "The program provided me with an insightful skill set and knowledge to include and apply teaching elements for student retention, understanding, and success;" I've been teaching 12 years and this program was a gift to better myself, develop understanding and compassion toward students, and to revise my methodologies," and "So much professional development is targeted at the disciplinary level. While this is of course valuable too, I think all faculty should do more professional development related to student needs and pedagogy." 
The frequency of responses regarding the effectiveness of specific components are shown in Figure 6. Ratings for these different components were generally good, with the lowest-rated being the online discussion boards, as in Cohort 1. Unlike in Cohort 1, the application project and other readings were the highest-rated.

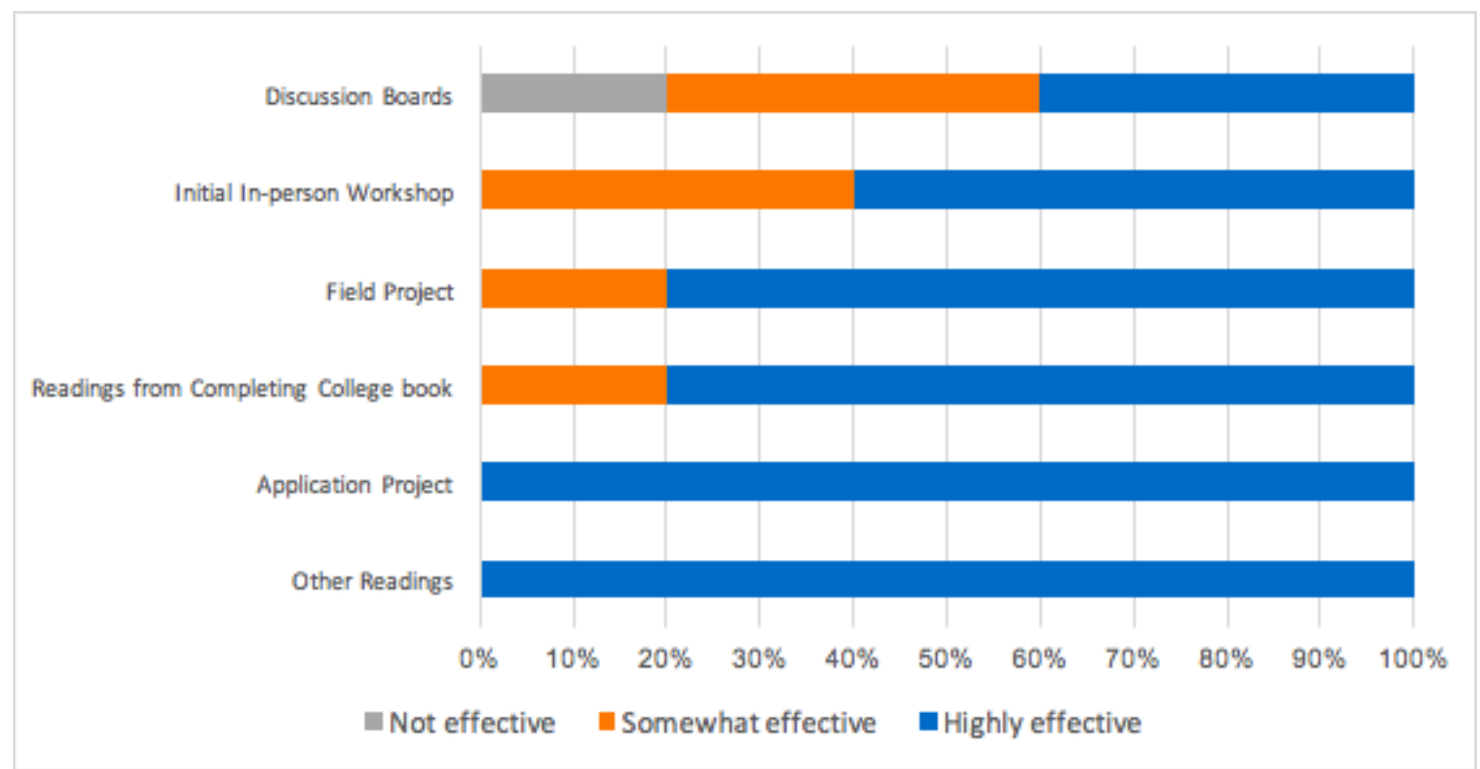

Figure 6. Mean ratings for the effectiveness of different components of PSP, ranked from lowest-rated to highest-rated, Cohort 2.

Below are some of the additional comments from the question about the Kickoff:

This initial event provided the excellent introduction to the program and my involvement.

I prefer the dynamics of face-to-face even when some cannot be present.

Good intro but the stats folks need to do a workshop with real data (and interaction) rather than just talking about what they can do

Comments in this section echoed in-person and email communication about the Kickoff session and the preference for in-person sessions and collaborations being favorable to working online.

Ratings on other items were nearly uniformly positive. Regarding the length of the program, five responded "about right" and one responded "somewhat long." For the pace of the program, four responded "about right," one responded "somewhat slow," and one responded "somewhat fast."

Regarding what would have helped them meet the expectations of the program, and suggested changes that would make it more effective, three respondents cited an online calendar and two cited more extensive discussion/explanation of expectations at the in-person workshop. Two said that nothing else was needed as the program was maximally effective as is. For suggested changes, decreased emphasis on discussion board participation was once again the most frequently cited (3 responses), one response cited increased breadth or scope in topics, and one response stated no changes were needed. 
In response to whether participants would recommend PSP to colleagues, every one of the respondents said "Yes, definitely," and some of the additional written comments were as follows: "I've mentioned this to several colleagues and what I had learned and how I can apply the concepts," and "Exposure like this keeps the important teaching activities and research in the forefront."

Other general comments on the program included mostly positive responses, specifically that the in-person and collaborative nature of the course as well as the projects and readings were useful. However, two respondents commented that they would have liked more explicit discussion about the expectations and time commitment.

With the caveat again that we had a very small number of responses to work with, these assessment data for Cohort 2 are encouraging, with the overall pattern of responses suggesting that participants had a valuable experience in return for time invested. As in Cohort 1, participants were somewhat critical of the online components, especially the discussions, but in general their impressions were highly positive. Participants also seemed to want more upfront information about the structure and expectations of the course, in particular, exactly when in-person meetings will take place. Conversely, they did not seem to appreciate the option of flexible or "to be determined" scheduling.

\section{Conclusions}

Given that faculty members are critical to the success of students, comprehensive faculty professional development programming is necessary. There is no silver bullet or one-size-fits-all approach to bolstering faculty members' practices based on a solid understanding of factors that influence academic persistence. We share our approach and experiences in the hopes of stimulating further developments in this neglected area of faculty professional development. This section is divided into observations, limitations, and recommendations.

Observations. We are encouraged by the results from the first two cohorts of the PSP. Faculty participated in and completed the program, an achievement that should not be taken for granted given the extraordinary limitations on faculty time particularly during the academic year. Comments from participants, work submitted as part of the application project, and ratings on our quantitative assessments all suggest a strong intent among participants to change their practices in ways that are likely to support student success.

Similarly, participant comments and ratings indicate that the program built important conceptual knowledge about academic persistence. In particular, participants referenced learning theories and concepts relating to mindset (e.g., lay theory), suggesting that these important ideas made substantial impacts on participants. A number also reported that in the course of the PSP, they felt more empathetic about or better understood the challenges faced by contemporary students.

This realization reflects what we believe is a more global objective for this type of program, which is for faculty to recognize the tremendous responsibility they have for student success. Barr and Tagg (1995) argued that in order to substantially improve student learning we must help faculty shift their focus from "teaching students" to creating learning environments that help students learn. For many faculty, this represents a significant mindset shift of their own. Traditionally, they may have focused solely on conveying content within a discipline, but this new mindset requires them to expand this focus to also include very mindful consideration of how they interact with students, what kind of feedback they offer and how they structure course features, such as formative assessments, to maximize learning. Umbach and Wawrzynski (2005) state that faculty members' "behaviors and attitudes affect students profoundly, which suggests that faculty members play the single most important role in student learning" and retention (p. 21).

Journal of the Scholarship of Teaching and Learning, Vol. 19, No. 1, February 2019. josotl.indiana.edu 
Coordinated, systematic professional development efforts are related to improved student outcomes, including higher retention and graduation rates as well as greater faculty satisfaction, engagement, and sense of belonging (Condon, Iverson, Manduca, Rutz, \& Willett, 2016). The coupling of a supportive, empathetic atmosphere for learning about student success with a scholarly view of multiple dimensions of academic persistence, sets the PSP apart as an innovative approach to faculty professional development (FPD). Many FPD programs take place in concentrated workshop-or conference-style formats, which is necessary when such programs are built around guest presenters or when scheduling limitations take precedence. In these traditional faculty professional development opportunities, participants typically learn about just one or a few concepts at a time but might not integrate across concepts into a larger conceptual framework with the potential for larger impacts on practice. For example, faculty might learn about belongingness in one workshop and about giving effective feedback in a different workshop, though explicit connections are not integrated into the programming, thus potentially reducing the likelihood that they are integrated into teaching practices.

PSP's extended format (8-10 weeks) incorporated meaningful, authentic assessments with a focus on reflection and application, emulating active learning-focused teaching that we encourage our faculty to practice in their classes. Given our goal to create a network of faculty who are recognized for their interest and knowledge related to student academic persistence, the cohort model provided faculty an opportunity to interact with and learn from colleagues from across the institution. In addition, PSP's extended time, highly collaborative, highly interactive format incorporated asynchronous online format and face-to-face sessions (blended learning or mixed modality techniques) to maximize the amount and quality of engagement, while minimizing the logistical issues (e.g. lack of flexibility in faculty schedules) and time pressures that limit faculty participation in FPD.

This blended strategy, however, gave rise to some surprising and ironic findings. The modality of the program was the source of most of the negative commentary from participants, with a number specifically stating that they preferred a face-to-face interaction for this type of work during existing in-person sessions and in personal communications. In an effort to adapt to the needs of the participants, more in-person sessions were made available, yet the same participants failed to attend.

Limitations. The feedback from faculty provides some important caveats, but we stand by the potential of blending as a model for FPD. Given the growing importance of online and mixed modalities for learning in higher education (see, e.g., Garrison \& Vaughan, 2008; Talbert, 2017), the blended model of PSP provided an important opportunity for faculty to understand and appreciate what it is like to be a student in this type of learning environment. Given that "expanding the use of blended and other technology enhanced course designs" is one of NAU's stated strategies to reach our student success goals, it is imperative that we provide relevant opportunities for faculty professional development.

Participant attrition was another limitation of the program. Although most participants who began PSP did complete it successfully, not all did, and this was felt to a greater degree in the second cohort because it was smaller to begin with. We can only guess the reasons for this might relate to the additional scheduled, in-person session where participants were asked to present the Field Project to the group. PSP saw 23\% of this cohort drop during this time, likely due to the synchronous and public nature of the presentation.

PSP leaders also saw missed deadlines, requests for extensions, and a number of incomplete assignments. While this is to be expected in an FPD program, most PSP participants were receiving "credit" towards the recertification of a FYLI course, giving more weight to their course completion.

A final limitation we wish to acknowledge is that we do not yet know whether the impacts of the program will translate into substantive, lasting impacts on faculty practice nor do we know whether

Journal of the Scholarship of Teaching and Learning, Vol. 19, No. 1, February 2019. josotl.indiana.edu 
any lasting impacts will translate into measurable gains in student success metrics such as course completion, degree progress or retention rates.

Recommendations. What should institutions wishing to establish similar programs keep in mind as they begin their planning? Here are our recommendations and lessons learned:

- Incentives are important for recruiting but need not—and ideally will not-be solely financial. We were successful in finding candidates by collaborating with an initiative already in progress, which could offer a different type of incentive (the opportunity to recertify within the program) as well as reach individuals who were already intrinsically interested in pedagogy and student success.

- Model the type of learning environment that you want faculty to create for students. Kuh, Kinzie, Buckley, Bridges, and Hayek (2006) found that students learn more in active, collaborative, and problem-focused classrooms where the environment is supportive and expectations are clear. We strongly emphasize experiential and active learning in the online as well as the face-to-face components.

- Consider a blended strategy but anticipate some significant faculty pushback. In future iterations of the program, we may address more explicitly the reasons for and the benefits of blended learning early in the program.

- Anticipate that there will be significant issues with late work, missing work, and attrition and have a plan for how these will be handled. Both MM and RK noted that it would be useful to have clearer expectations for success in the beginning of the program. This might mean that $80 \%$ of assignments need to be completed in the style of specifications grading (Nilson, 2015) in order for participants to successfully complete the program.

- Note that participants will need advanced planning, reinforced deadlines, and several reminders about upcoming assignments. Our participants even recommended the online calendar in the LMS.

- Choose materials and readings that are not only applicable, but also meet high standards of scholarship. Faculty respond well to approaches that emphasize critical inquiry and empirical evidence, and these can complement the more empathic, interpersonal side of teaching.

- Realize that cohort size plays an important role in the participant experience, particularly with respect to how participants interact with the facilitator. Having a larger cohort can be useful in creating a diversity of experience at the university but can be more difficult for the facilitator to manage during in-person sessions and in online discussion boards. Smaller groups might allow for personal relationships to develop among participants/the instructor, but it might feel more casual.

- Recognize that the mere act of creating a class environment for faculty is useful. Several participants commented about how PSP reminded them of what it was like to be a student again: having deadlines, struggling with technology, navigating texts, etc. They claimed that this experience helped them to be more empathetic towards students. In a personal communication with one participant, this was clearly evident: "I've been out of town since last Friday. I had thought that I had submitted my assignment, but as I'm prepping my 3-minute talk, I realize that I hadn't! I've uploaded the assignment to BbLearn. I feel like I'm more in tune with the student experience already!" 
We encourage other institutions to share their efforts to leverage faculty as part of their student success efforts. We implore institutions to invest in faculty professional development as a fundamental part of their overall strategic plan for improving graduation rates and ensuring student success.

\section{Acknowledgements}

We obtained Institutional Review Board approval for reporting assessment data and participant comments for this project. Portions of this project were also presented in a guest blog post for WCET and some of the text from that post also appears in this publication. We would like to thank NAU's Office of Curriculum, Learning Design and Assessment, the Registrar's Office, Enrollment Management and Student Affairs, the Office of Faculty Professional Development, and the ELearning Center for their gracious support in the form of expertise, staff time, and support to the PSP facilitators. We offer heartfelt thanks as well to the 2017-2018 Persistence Scholars for their time, hard work, and willingness to be a part of a new and evolving program.

\section{References}

Barr, R, \& Tagg, J. (1995). From teaching to learning: A new paradigm for undergraduate education. Change, November-December, 13.

Commission on the Future of Undergraduate Education (2017). The Future of Undergraduate Education, The Future of America. Cambridge, MA: American Academy of Arts and Sciences.

Condon, W., Iverson, E. R., Manduca, C. A., Rutz, C., \& Willett, G. (2016). Faculty development and student learning: Assessing the connections. Bloomington: Indiana University Press.

Garrison, D.R., \& Vaughan, N.D. (2008). Blended learning in higher education: Framework, principles, and guidelines. San Francisco: Wiley.

Kuh, G. D., Kinzie, J., Buckley, J. A., Bridges, B. K., \& Hayek, J. C. (2006). What matters to student success: A review of the literature. Retrieved from nces.ed.gov

Miller, M. D., \& Scarnati, B. (2014). Engaging faculty for student success: The First Year Learning Initiative. Teacher-Scholar: The Journal of the State Comprehensive University, 6, 1-14.

Nilson, L. B. (2015). Specifications grading: Restoring rigor, motivating students, and saving faculty time. Sterling, VA: Stylus Publishing.

Talbert, R. (2017). Flipped learning: A guide for higher education faculty. Sterling, VA: Stylus.

Tinto, V. (2012). Completing college: Rethinking institutional action. Chicago: University of Chicago Press.

Umbach, P. D., \& Wawrzynski, M. R. (2005). Faculty do matter: The role of college faculty in student learning and engagement. Research in Higher Education, 46, 153-184.

Journal of the Scholarship of Teaching and Learning, Vol. 19, No. 1, February 2019.

josotl.indiana.edu 